\title{
Ruffling the Calm of the Ocean Floor: Merging Practice, Policy and Research in Assessment in Scotland.
}

\author{
LOUISE HAYWARD, MARK PRIESTLEY AND MYRA YOUNG
}

\begin{abstract}
The formative Assessment for Learning proposals outlined by Black and Wiliam (e.g. Black et al, 2002) have been well publicised. Since 2002, in its Assessment is for Learning programme, the Scottish Executive Education Department (SEED) has been exploring ways of bringing research, policy and practice in assessment into closer alignment using research on both assessment and transformational change. This paper focuses on one project within Assessment is for Learning, in which pilot primary and secondary schools across Scotland were encouraged to develop formative assessment approaches in classrooms. They were supported in this by researchers, curriculum developers and local and national policy makers. The paper examines the rationale and methods behind the enactment of formative assessment in these schools. It draws upon evidence provided by the interim and final reports of participating schools to draw conclusions about areas of success within the project and potential barriers to the project's future in its evolution from pilot to national programme.
\end{abstract}

\section{INTRODUCTION}

'Hurricane winds sweep across the sea tossing up twenty foot waves; a fathom below the surface turbulent waters swirl while on the ocean floor there is unruffled calm' (Cuban, 1994, p. 2). Thus, the American educator Cuban described the effect of education reform on classroom practice. His metaphor vividly encapsulates the tendencies that occur all too frequently when policy makers attempt to instigate change through top-down, centreperiphery strategies; as noted by Goodson (1994, p.13), 'frenetic activity in the 
foreground (tends to) obscure some of the deeper continuities in the background'. If centrally instigated reform has failed to impact on classroom practice, it is not due to lack of effort on behalf of policy makers. Reform, as Levin (1998) suggests, has reached epidemic proportions; there has been 'policy hysteria' (Stronach \& Morris, 1994), as governments increasingly seek to utilise education as a policy lever to maintain control over areas such as the economy in the global age (Priestley, 2002). And yet classroom practice seems essentially unchanged; indeed teaching can be seen as a 'technology that is especially resilient to change' (Spillane, 1999, p. 143). According to Swann and Brown (1997, p. 91) 'Past records for curriculum initiatives show extraordinarily modest levels of pedagogical implementation, in part because curriculum innovators have failed to start 'where the teachers are'. This paper examines how a particular innovation has been promoted in Scottish schools. The innovation, Support for Professional Practice in Formative Assessment, is part of Scotland's Assessment is for Learning programme. It can be seen as an attempt to change and enhance the pedagogical practice of teachers in Scottish schools, through the development of formative assessment approaches which research (e.g. Black and William, 1998a; Black et al, 2002) suggests can improve learning and attainment. There is thus a clear agenda from the Scottish Executive to enhance the relationship between research, policy and practice.

The paper briefly examines the political background to the project, before considering the rationale for stimulating and sustaining change. Finally we draw upon the project evaluation reports written by participating schools to examine the preliminary evidence of changed practice, and the likely barriers to sustainability.

\section{ASSESSMENT IS FOR LEARNING: THE CONTEXT FOR DEVELOPMENT}


The SEED programme Assessment is for Learning was initiated in 2002. The programme seeks to articulate a holistic assessment policy for Scottish schools. It comprises three sets of linked projects designed to offer opportunities for teachers, researchers and policy makers to work collaboratively:

- Professional Classroom Practice

- Monitoring and Evaluating using Assessment Data

- Quality Assurance of Assessment Information

We recognise that all three issues are interdependent, but have focused this paper on the findings of the Professional Classroom Practice project concerned specifically with improving formative assessment in classrooms (assessment for learning). The central purpose of this project, Support for Professional Practice in Formative Assessment, was to explore ways of embedding changed pedagogy and greater levels of student participation, initially in the project schools and from there to every school in Scotland.

In the assessment arena in Scotland, there already existed clear principles, Assessment 514 (SOED, 1991), advocating the centrality of formative assessment. However, subsequent evidence (Swann \& Brown, 1997; HMI, 1998) suggested that the national assessment policy had produced little impact on classroom practice. In the light of this report, a national consultation on the future of assessment in Scotland (Hayward et al, 2000) was instigated by the Scottish Executive, involving major stakeholders. There was clear, almost unanimous support for the principles of Assessment 5-14, but stakeholders identified three major linked areas where change would be necessary if these principles were to be translated into practice in classrooms across Scotland. First, work was needed to understand the practical implications of formative assessment in day-to-day 
classrooms. Second, the relationship between assessment for learning and assessment for measurement should be revisited. Third, the bureaucracy of assessment had to be minimised to allow the focus to remain on learning rather than on the collection of evidence as an end in itself.

The consultation indicated that many teachers perceived that the education agenda propagated by the Scottish Office (later Executive) Education Department (SOED; SEED), by Her Majesty's Inspectorate of Education (HMIE) and by local education authorities was centrally concerned with what Black (2001) describes as the assessment dream to drive up standards by measurement, in particular by testing. In this context, the Assessment 5-14 policy (SOED, 1991) seemed at odds with the prevailing ethos and although it was regarded by many teachers and others as being consistent with their own views of what constituted sound professional practice, they felt obliged to focus on what they believed to be the real priority, national testing. The evidence from the consultation also suggested that there was a perception in the late 1990s that the climate was gradually changing, allowing teachers to begin to be a little less concerned with the measurement agenda. However it was also clear that if this perception were to be sustained and developed, and if tension between policies was to be avoided, there would have to be clear and consistent messages from national and local policy makers, from HMIE and from curriculum developers about the importance of developing formative assessment.

Of course ensuring that policies are coherent and grounded in research does not ensure their ready adoption in practice. Such an assumption implies a functionalist and social engineering conception of policy and research that ignores the heterogeneity and social contingency of contexts within which policy has to take root, as well as the role of 
accumulated practitioner knowledge. Notwithstanding, Guile (2002) argues that, in England and in the EU, policies are traditionally based on such impoverished models. Typically the relationship between research, policy and practice is conceived as practice acquiring pre-existing knowledge from research or policy; rarely is it constructed in terms of supporting individuals to understand research and policy and to produce new knowledge from these foundations.

The relationship between research and practice in the field of formative assessment provides a cogent example of this phenomenon. The Black and Wiliam (1998a) meta analysis of the research evidence suggests that there are fairly clear and consistent findings to demonstrate the positive impact of formative assessment on children's learning. However their study also recognises that the relationship between research findings and classroom practice is less certain. What might be the reasons for the lack of consistency between the research evidence and practice? For example, might it be the result of teachers being asked to engage in practices inconsistent with their own views of what constitutes quality in learning. Or could it be, as suggested by Doyle and Ponder, (1977) that even where policy and research is congruent with teachers' values it may not be practical? It may lack instrumentality, either lacking the clarity and/or kind of detail necessary for other teachers to translate ideas into practice, or simply be too difficult to operationalise under classroom conditions. Or the policy may involve costs, such as the perceived risk of negative inspection reports

The design of the Assessment for Learning programme was intended to overcome these barriers. Three of the most significant influences are described here. The first emanated from reflections on previous policy initiatives. The original Assessment 5-14 policy 
(SOED, 1990), which drew upon research findings, was premised on an assumption that if policy was informed by research, then practice was simply a question of implementation. Staff development was perceived as the means by which practitioners were supported to enact policy proposals, a model not dissimilar to the process described by Guile (2002). This ignores the power that teachers have to mediate change. As Hargreaves (1997, p. x) argues, teachers don’t merely deliver, they ‘develop, define and interpret'. Such mediation of reform takes many forms including what Osborn et al (1997) have described as conspiratorial mediation: that tendency for teachers to comply strategically with the reform in question, while implementing in selective ways that fit their prior practice. The second major influence came from the work of Wiliam and Lee (2001). They had begun to investigate the relationship between ideas from research and practice in a number of English secondary schools in the King's-Medway-Oxfordshire Formative Assessment Project (KMOFAP) project (see also Black et al, 2002). This project sought to take forward issues emerging from the Black and Wiliam review (1998a). Teachers in the project worked with researchers to explore how ideas from research might be translated into the varying contexts of different classrooms. Teachers were not told what to do but rather invited to experiment, to explore, develop and evaluate approaches to formative assessment in their classrooms. A third set of influences came from work on transformational learning, in particular from Senge and Scharmer and their analysis of community action research approaches. Transformational learning within and across communities, they suggest,

...rests on a basic pattern of interdependency, the continuing cycle linking research, capacity-building and practice: the ongoing creation of new theory, tools 
and practical know-how. We believe this pattern is archetypal and characterizes deep learning at all levels .... The unifying feature of all is a commitment to integrate the knowledge-creation process to sustain fundamental social and institutional change, be it the local schools or multinational corporations. (Senge \& Scharmer, 2001, p. 248)

These influences led to certain key design features in the Assessment is for Learning programme. The programme had to build from where people were: professionally, individually, collectively and politically. Learning for teachers, researchers and policy makers in this project is not simply about the acquisition of knowledge and skills, but has to involve learning how to transform communities of practice. In Cuban’s (1994) terms it must avoid the creation of the hurricane and perhaps gently ruffle the calm of the ocean floor. Ownership of change is recognised as being a key issue in promoting and sustaining change. Paechter (1995, p. 50) suggests that: 'teachers are more likely to be committed to an innovation if they are able to recognise their contribution to its inception'. There is an explicit recognition within the formative assessment project that 'to restructure is not to reculture' (Fullan, 1993, p. 49), and 'while policy makers and reformers at all levels of the system are crucial if reforms are to be enacted locally, teachers are the key agents when it comes to changing classroom practice’ (Spillane, 1999, p. 144).

It might be argued that traditional policy led staff development, even when research based, has paid insufficient attention to the power of classroom teachers within their classrooms. An important feature of the formative assessment project has therefore been the attempt to begin to change the power dynamic amongst teachers, researchers and 
policy makers. Assessment is for Learning has provided teachers with the impetus through ideas and resources, but the nature of the translation of these into practice has been primarily the responsibility of teachers involved with the project. This is consonant with Hammersley's cognitive resources model of research, in which research contributes to 'bodies of knowledge which may be used as resource by practitioners' (Hammersley, 2002, p. 97) in addition to their existing banks of practical and theoretical knowledge. The project thus involves bringing closer the separate worlds (Hammersley, 2002) of teachers, researchers and policymakers. This approach provides a model with the potential for real collaboration and for the creation of new thinking across research and practice communities, rather than creating what Ball (2001, p. 226) describes as ‘unselfconscious classroom drones’.

\section{TEACHER DEVELOPMENT IN FORMATIVE ASSESSMENT}

As previously indicated, this paper focuses on the development of one strand of the Assessment is for Learning programme, namely project one, Support for Professional Practice in Formative Assessment. Participating teachers had access to the cognitive resource (Hammersley, 2002) of the research ideas, including the testimonies of teachers from the KMOFAP project, who shared with them strategies they had developed as they had tried to explore the relationship between research findings and their own classroom practice. These strategies had been developed for example, to improve questioning techniques, to enhance teacher feedback to students, to promote more effective self and peer assessment and to open up the assessment process by developing and sharing criteria. (Black et al, 2002). The project required teachers in primary and secondary schools to undertake planned interventions in their classroom practice, and to record and 
evaluate the effectiveness of those interventions. In setting up such a project, Black and Wiliam advocate:

The first essential step is to set up a small local group of schools, some primary, some secondary, some inner city, some from the suburbs, some rural, with each committed to school based development of formative assessment and to collaboration within their local group. (Black \& Wiliam, 1998b, p. 16)

In total, 35 schools, disparate in size, catchment and culture, were nominated by local authorities to participate in the Assessment is for Learning programme. They represent every local authority in Scotland, as well as the independent sector, and comprise 16 primaries, 14 secondaries, two junior high schools (P1-S2), two all-through schools (P1S6) and one special school. One school subsequently left the project when one of the teachers was promoted elsewhere and the second became ill.

The remainder of the paper draws upon interpretive analysis of the interim and final evaluation reports from these schools to judge the effectiveness of this policy innovation in affecting classroom practice. These reports, submitted by 33 of the remaining 34 schools between December 2002 and May 2003 do not follow a fixed format, but vary greatly in tone and form; for example some schools chose to submit written reports, and others produced video diaries recounting their experiences on the project. Nevertheless, despite this heterogeneity, the reports provide a rich and authentic evidence base of teacher reflection upon the enactment of a set of strategies within a diverse range of classroom settings; they thus provide a useful insight into the meanings that teachers give to the changes that are taking place in their classrooms. 
The reports are homogenous in one limiting respect: they indicate that all participating teachers considered the project a success. However, visits to the schools, discussions with teachers and headteachers, and critical reading of the reports, indicate the existence of a phenomenon noted by Spillane (1999): that some teachers believe that they are enacting the initiative when there seems little evidence to support that view. Our analysis suggests that some schools have managed to develop formative assessment ideas within their classrooms more successfully than others. Of the schools that stayed the course, 14 appear to have embraced the formative assessment strategies wholeheartedly, while another 14 seem to have made good progress in refining their practice. On the basis of the same observations, five schools seem to have gained less from their involvement. Given that no school was coerced to participate, and that each school was given identical funding and could avail itself of support from the national development team and its local authority, it is interesting to try to account for this difference.

A number of issues were explored in seeking to understand why different teachers experienced differing levels of success:

- Reasons for joining the project - with possible effect on motivation.

- The teachers as learners themselves - their apparent willingness or otherwise to read, reflect, engage with and, discuss ideas and to share practice and materials.

- The teachers' expressed empathy with the aims of the project.

- The level of interest and support from local authority personnel - assessed by whether or not they were in regular contact. 
- The level of interest and support from school senior management - judged on whether or not they were present at meetings with development officers, and on evidence of scheduled regular meetings to discuss the project with participating staff.

- The actual involvement in the project of key staff in the school - as for instance in the case of a teaching headteacher.

We have also adapted a schematic model for curriculum change (Priestley, 2003) to explain and contextualise the influences that have been brought to bear upon the project one schools and teachers, and which may have impacted on their capacity to introduce formative assessment in a way that might influence long-term pedagogical practice (see figure one). Central to this model is the construction of teachers, researchers and policy makers as active learners, rather than the traditional view of teachers as passive conduits of policy. The use of the term scaffolding to denote the support mechanisms established for participating schools is redolent of Vygotsky's (1978) constructivist theories of learning, in particular the notion that learners need support in order that they may negotiate the zone of proximal development (ZPD) inherent in any new learning situation.

Many writers have examined the factors that make for successful innovation. For instance, Cowley and Williamson (1998), in their comparison of English and Australian curriculum developments, identified ten ingredients of successful curriculum innovation. These included: support (financial, professional and psychological); flexibility in planning, the designation of key teachers with responsibility for implementing change; professional development workshops; allowance for staff to work at their own pace; 
effective collaborative relationships; the openness of staff to new ideas; recognition by students of the change; and ongoing evaluation. Spillane’s (1999) 6 Ps model stresses similar factors; he sees successful innovation as involving the conjunction of policy, profession (including notions of the community of practice), pupil responses, public responses, the private sector and the personal resources of the teacher. The change model reflects some of these factors as they apply to Assessment is for Learning in its Scottish context.

\section{Insert figure one}

\section{THE SOCIAL CONTEXT OF CHANGE}

An understanding of the social context within which reform is rooted is essential. According to Hargreaves and Fullan,

The process and success of teacher development depends very much on the context in which it takes place. The nature of this context can make or break teacher development efforts. Understanding and attending to the ecology of teacher development should therefore be an important priority for teachers, administrators and researchers alike. (Hargreaves \& Fullan, 1992, p. 13)

A useful starting point for this analysis is to return to Swann and Brown's (1997) implication that innovation should start from 'where the teachers are'. From a Gadamerian perspective (Gadamer, 1977), this involves consideration of not just the present horizon, but also the past horizon, namely the past trajectories that have brought the teachers to where they are. As Helsby and McCulloch (1997) remind us, reform is ultimately a dialectical process; while teachers mediate innovation in many and often 
unexpected ways, the dynamics operate in both directions, and teachers emerge from the process changed by their experiences. The latter process is the major goal of the architects of particular reforms, but conversely policy makers need to take account of the massive potential of the former in rendering innovation useless. Such attempts must surely take account of the social context within which teachers operate, and in many cases any attempt at innovation must seek to either modify that social context, or even to construct a new social ground for reform (Olson, 2002). According to Olson, teacher tradition is a powerful and often shared experience, and not one to be overcome easily. The discourses of teaching are, like all discourses, 'historically constructed over time, and through a weaving of multiple historical trajectories' (Popkewitz, 1997, p. 149), and once established are difficult to challenge and dislodge. In short, if prevailing practice, attitudes and culture are not well-disposed towards change, then innovators have to pay more attention to the mechanisms for facilitating reform. Popkewitz (op cit), drawing on Wittgenstein's rope metaphor for change, pointed out that the strength of the rope is not dependent on the length of its constituent strands, but on the number of strands that interweave at a given point. In applying this metaphor to educational change, strands may represent contextual factors such as teacher capacity and will to change, institutional culture and the nature of prior practice. They may also represent innovation factors such as resourcing, professional support and the quality of communication. If all of these factors co-exist in good measure, then innovation stands a good chance of succeeding; however if some are missing, or weak, then clearly innovators need to boost the strength and number of other factors within their control. Given the obvious lack of control over many of the contextual factors, the importance of ensuring the existence of many strong 
support strands must therefore be stressed. In other words, the external reform levers need to be strong to compensate for a potential lack of capacity and will to reform.

So, where are Scottish teachers, and specifically the teachers embarking on this project, in relation to formative assessment? What is the social context for reform, as indicated on the model? In terms of socio-political trends, and as we have already indicated, there is a clear line of development towards Assessment is for Learning in prior assessment initiatives. However, as also noted, there is some evidence that the previous initiatives did not firmly embed in schools. For example, Swann and Brown have pointed to the lack of internalisation of the ideas contained in the 5-14 guidelines:

The official 5-14 evaluation reported that by autumn 1992 the assessment guidelines had been read by 62\% of primary teachers, and by spring 1993 by most secondary teachers. While teachers in general have been ready to respond to direct questions about the guidelines, there was no evidence in our research of the internalisation of ideas from the guidelines into teachers' classroom thinking. (Swann \& Brown, 1997, p. 103)

The lack of such internalisation must surely have an effect on the ability of teachers to understand and subsequently take forward innovation focusing on formative assessment. Such analysis is mirrored by Black and Wiliam (1998, p. 10), within the wider context of their worldwide review of assessment literature; in this they state that 'formative assessment is not well understood by teachers'. This is not to posit a deficit view of teachers, but rather implies, as we have suggested earlier in the paper, that the structures within which teachers operate do not necessarily encourage innovation, even when it has official sanction. For instance, system wide trends towards target setting encourage 
convergent forms of assessment, rather than the divergent assessment (Torrance \& Pryor, 2001) implied by Assessment is for Learning. One can infer that, despite the existence of the Assessment 5-14 guidelines (1991), with their emphasis on formative assessment, socio-political trends are more conducive to assessment for measurement, than to the participative and social constructivist thinking that underpins the work of Black and Wiliam (e.g. 2002), and upon which Assessment is for Learning is predicated.

Linked to this is the nature of much prior practice amongst the target teachers, and the institutional cultures within which they operate. The inherent conservatism in terms of pedagogy of many Scottish teachers, especially in secondary schools (Bryce \& Humes, 1999), is a major contextual factor that could be seen to inhibit the will to embrace the innovation. For example, the project interim evaluations demonstrate that teachers in primary schools seemed to have less difficulty introducing and developing formative assessment approaches, and in making up their own variations on suggested strategies than did their secondary colleagues. In our view, this is partly a question of pedagogy and underlying assumptions about epistemology, on the part of teachers and managers (including at an authority level) and of policy makers. In secondary schools, didactic forms of teaching and individualistic modes of learning are more common, and the use of worksheets is commonplace. 'Rootedness in an assessment-focused subject sub-culture' (Paechter 1995, p. 88) is a major cultural constraint on the greater implementation of formative assessment, because of its encouragement of teaching based on the transmission of content. The upper school curriculum is geared ultimately to examinations, and 'the transmission model of teaching and learning implied in most of 514 was assumed to be unlikely to tip teachers' thinking towards constructivism' (Swann 
\& Brown, 1997, p. 98). It is also a question of ontological assumptions about teacher identity. There are two possible aspects to this. Teachers may possess firmly held beliefs about the role of the teacher in the classroom, which may or may not be compatible with the participative methods of learning advocated by Black and Wiliam (e.g. 2002).

Secondly, there are fundamental questions about how teachers see themselves as lifelong learners; for example, it is evident from our data that teachers who showed little interest in reading, reflecting, accommodating, discussing and sharing practice and materials have enjoyed less success with the project.

Participation in the Assessment is for Learning project was voluntary; this initially suggests that the participating teachers would be likely to be enthusiastic about Assessment is for Learning at the outset. Nevertheless there are some qualifications to make, especially in respect of the circumstances in which the schools were nominated. The schools fall into three categories. The first includes those who had been inspected by HMIE recently, and had been left with recommendations to review the assessment process. This group also included schools that had themselves identified assessment as a priority for action. For these schools, the project was an opportunity to examine their existing practice, access research literature and receive additional support (by way of funding and advice) to enable them to change their practice. Other schools already had a reputation for good practice in their own local authority, or had visionary headteachers; support from the project would provide a research base for reflection on their existing practice and encourage a honing and refining of classroom skills. In both these cases, one would expect a degree of enthusiasm for the innovations proposed, although the impact of the link with the HMI report is a complicating factor for schools in the first 
category. In the third case, matters were potentially different; schools belonged to a cluster of schools within the scope of the nominating education officer, and there was little choice offered. It is interesting to note that some of the individual teachers involved had no clear idea why they were approached, and some ascribed it to nothing more than a fortuitous meeting with a senior manager in the corridor. Teachers from these schools often attended the initial conference expecting to be provided with some instant solution to assessment problems, and were subsequently disappointed to find no such philosopher’s stone. More commonly they expected external direction rather than being provided with a 'readerly' set of ideas. In such circumstances there is a stronger likelihood of resistance and scepticism to their participation.

\section{PROMOTING SUCCESSFUL CHANGE}

In the change model, the strands described coalesce to form a single, thicker strand that can be usefully described as the capacity and will to reform (Spillane, 1999). The strength of this will depend to a large extent on the strength of the constituent strands. Thus we can predict, for example, that schools with a prior tradition of embracing participative learning will require less support in implementation. Furthermore, teachers who see value in an innovation will be more likely to work with it and to explore its potential in practice despite a lack of support. As Hargreaves (1994, p. 22) reminds us, 'without desire teaching becomes arid and empty. It loses meaning'. Conversely, where the social contextual strands are weak, attention will need to be given to the creation of additional strands to ensure the success of the project. These additional strands fall into two broad categories. The first of these are formal inputs including the policy impetus for the project and its associated funding, and the scaffolding provided and enabled subsequently 
by curriculum developers, teaching colleagues, researchers and policy makers; the second are the often non-formal contextual factors that emerge from the social context for reform, and which are specific to the innovation; these can be catalysts for change, although conversely they can easily become inhibitors (see figure one).

First let us examine the impetus and scaffolding for the project. Clearly the impetus for the project has been provided by the Assessment is for Learning programme. Schools were offered substantial additional funding to participate and the release of funding was linked to the production of action plans, interim and final evaluation reports. This was accompanied by a large scale programme of meetings to disseminate research and policy information and to provide forums for discussion between teachers engaged with the project; these included conferences (with input from teachers from England who have been involved in the KMOFAP project), recall meetings to bring together teachers on a regional basis, and the establishment of a website and bulletin board. Support networks were established comprising development officers from the body charged with running the project, LTScotland, representatives from universities and local authority assessment coordinators. The programme was designed to build in the potential for significant scaffolding for schools and teachers. This scaffolding was created in recognition that 'reform can give rise to risks of personal failure, conflict and frustration in situations where support for teacher development is lacking' (Olson, 2002, p. 131).

The scaffolding provided by the project support mechanisms prompts teachers to adopt new practices, which in many cases would have been known to them, but which may have been seen in the absence of support as involving considerable costs (Ponder \& Doyle, 1977). While the project's emphasis on learning was largely congruent with 
participating teachers' values, in some cases the project entailed teachers adopting practices that ran contrary to existing ideas about practice, as evidenced by the open scepticism of many teachers in the early days of the project. This subsequently involved them unlearning and discarding deeply held beliefs about such practice. The introduction of new ideas, 'as reform levers (gets) teachers ... to think differently about their practice, by raising questions about existing practices, and prompting the construction of alternative practices' (Spillane, 1999, p. 154). In the words of one experienced primary teacher (a teaching headteacher):

It has to be said that during this project my view of education has undergone a 'sea-change'.... this has not happened often during my teaching career and is a bit unsettling to someone of my age! (final report, Woodend Primary School, 2003).

Thus by trying new ideas, teachers potentially see strengths and inadequacies in their existing practice, and new ideas become embedded in new forms of practice. In Gadamerian terms, understanding and interpretation of the new ideas becomes transformation and indeed self-transformation (Madison, 1999).

Spillane (1999) has stressed the importance of amplification by local officials and managers in encouraging reform to take root. In the formative assessment project, education authority assessment coordinators were undoubtedly better placed than the development team to provide ongoing local support for schools, but while this may have added value in individual schools, it did not appear to be crucial to success. Only a third (5) of the most successful schools perceived that they enjoyed regular supportive visits from their education authority link and three out of the five schools where progress was 
less evident appeared to have been well supported by their education authority assessment co-ordinators.

All schools where ideas on formative assessment had had a significant impact on practice were led by headteachers, or their deputes, who were well-informed and highly supportive of their staff. A culture of monitoring and evaluation prevailed in these schools, with a strong emphasis on personal and professional reflection. For example, two of the headteachers had class commitments, and led by example; another had styled herself 'research partner' to her young teachers; in a third school individual teachers audited their own professional practice prior to the annual development planning process. The headteachers of schools where formative assessment had impacted on practice also actively demonstrated their commitment to the programme, for example by attending meetings when development officers from LTScotland visited their schools. There was an air of confidence amongst the teachers in this group. They were proactive in establishing teacher contacts, in sharing materials, either physically or through the website, and in initiating communication with the LTScotland development officer. In contrast, teachers in schools where success was less pronounced did not tend to seek advice as actively or make contact with others, despite encouragement to do so; they often claimed that they lacked time. In circumstances where headteachers articulated support for the project but gave few signs of this support to teachers in their schools, teachers often interpreted their lack of engagement as opposition to the programme. In one school, teachers felt they had no 'champion' in the school and felt isolated and vulnerable. They felt awkward about making legitimate requests arising from project involvement (e.g. time to meet with each other) and came only for part of their meeting 
with their education authority group because they were afraid of causing their headteacher’s displeasure if they were away for too long. In discussion with the development officer, the teachers did not want to raise the issue or have the issue raised with the headteacher. They were fearful of 'rocking the boat'. Other evidence (e.g. from conversations between the development officer and the headteacher) would suggest that the headteacher was not in any way opposed to their involvement. In another school there was a designated member of the school management team for the project who expressed support but never managed to attend meetings, for perfectly legitimate reasons. The teachers commonly made reference to feelings of powerlessness. In both of these schools teachers were concerned about the time-consuming nature of the formative assessment approaches. One teacher described the major problem as,

mainly my reluctance to let go of the reins. The close reading was good, but it took 6 periods after the pupils had completed the paper for peer assessment and feedback. This seems an awfully long time and I started to worry about completing the course requirements at this rate (final report, Streamside High School, 2003)

Changes in classroom practice were more common in schools where several teachers were taking part in the project. The synergy, activated either by the involvement of several teachers in the same school or by talking to teachers in other schools, was undoubtedly important. In one case a highly motivated individual working in isolation made significant changes, but it is evident that such progress was greatly facilitated by the existence of a supportive senior manager who was prepared to enable teacher 
autonomy; such support represents a significant contextual catalyst to promote genuine change at a classroom level. The teacher concerned reported that:

school cooperation has been a huge factor in the success of this project. They allowed me to spend the budget as I saw fit, and as a result we were able to buy lots of assessment materials (including books, ICT and audio-visual equipment), which made the project run more smoothly. There has also been a lot of support in terms of providing cover.... (final report, Townview Academy, 2003).

This teacher's choice of terminology is interesting; the term 'allow' suggests a particular power relationship, the redistribution of which has led to feelings of greater empowerment. To us it appears that an important factor in facilitating change is a redistribution of power relationships within the schools concerned.

In the schools experiencing greatest success, it is clear that staff received the support they desired, however that was conceptualised, and that their social context provided fertile ground for change. Consequently change was seen as invigorating. In schools where teachers found change more difficult but were willing to persevere none of the teachers were resistant to change, but the context of school and local authority scaffolding, values and structures was less accommodating. In schools where it became difficult to detect change despite a stated commitment to the aims of the project, teachers seemed particularly challenged by the ideas. They found it difficult to allow the learners greater control of their own learning and were more likely to be anxious about the requirements of the final report. Generally they felt less satisfied with progress. At best passive disinterest affected motivation; at worst, the context actively inhibited change. In discussion, none of the teachers in this group revealed an appreciation of the impact of 
the Kings College research (e.g. Black et al, 2002), and they did not engage with it. Strategies were attempted in isolation, without recognition of the underpinning ideas and research.

In these cases there were considerable contextual inhibitors, which militated against successful change. As is the case with contextual catalysts, these inhibitors have existed from the start of the project, but have often been obscured by the initial enthusiasm for the strategies. As the project progressed, they have had a tendency to become more visible, and thus exerted a damaging effect on the progress made by schools and teachers. For example, inflexible programmes of study created difficulties, unless teachers had the confidence to demand that the curriculum be modified to accommodate pupils learning through formative assessment. Some schools had adopted managerial solutions to the instruction to drive up standards, paying scant regard to pupils’ prior learning or to communication between professionals engaged with the project. In one school, subject teachers were given no information on pupils' levels of achievement, yet significant time and effort was spent charting pupils’ results in baseline testing, and indicating perceived instances of over- and under-achievement. In this school, no meetings had taken place between the teachers involved, or with the headteacher, and no evaluation of existing practice or materials had taken place. In another school, the existing policy was to set pupils in S2. Two months into the project, the SMT decided to adjust S1 classes immediately, extending the setting policy into S1, so that pupils involved in the project were unsettled and eventually ceased to be recognisable as a group.

One of the most powerful contextual catalysts identified by teachers participating in the project was the reaction of pupils to the changes. Many writers (e.g. Cowley \& 
Williamson, 1998; Spillane, 1999) have pointed to the increased likelihood of teachers internalising reforms if they prove to be popular with pupils; this certainly seemed to be the case with the teachers reporting most success. Examples abound; for instance one secondary teacher reported that she had rediscovered the joy of teaching due to the impact of strategies adopted.

Since adopting the two broad strategies in my S3 classes, I have used them in all my classes. I've rediscovered how much fun teaching can be, and the pride you feel when pupils work to the best of their ability and take on responsibility for their own learning (final report, Bankhead Academy, 2003).

Conversely one of the most powerful inhibitors identified by teachers was a widely held perception amongst teachers that the formative assessment strategies will not be welcomed by HMIE when schools are inspected.

I also feel that the authorities need to back the project fully.... it needs to be recognised by whole school, Local Authority, Scottish Office and HMI. This would reassure teachers they have the support required to implement this strategy (final report, Seaview Academy, 2003).

Such perceptions may be erroneous, but do highlight the potential tensions between assessment for learning and assessment of learning. They also highlight the importance of ensuring that ideas from innovation in formative assessment are reconciled with notions of assessment for measurement. 


\section{THE FUTURE?}

Assessment is for Learning is a programme attempting to gently ruffle the calm of the ocean floor; it aims to change its landscape on a permanent basis rather than to create yet another short-lived hurricane in Scottish education. The early signals from the pilot schools demonstrate that progress towards this goal is occurring in many of the settings where the project strategies have been adopted. More recently, our conclusions have been supported by evidence from the external evaluation of the formative assessment project, carried out by the University of London Institute of Education (Hallam et al, 2003). Both our analysis of the project data and the IoE evaluation have highlighted the increased levels of pupil engagement, pupil confidence and pupil enthusiasm reported by teachers across the pilot project. Teachers have frequently made reference to evidence of deeper learning amongst their students and noted the particular impact on children who find learning hard. Moreover, there is substantial evidence of similar increases in engagement, confidence and enthusiasm on the part of the teachers in the project. Teachers have consistently reported that involvement in the project has led them to think harder and to work harder than before, but that this is ultimately satisfying. In the words of one teacher:

Over the session, I have been delighted to watch research documentation develop into chalkface practice ... Taking part in this project is the most effective development work I have undertaken in my career ... It's been hard work but its impact on our pupils has been worth it! (final report, Hillside Primary School, 2003).

Our analysis suggests that, ideologically, many teachers appear to be comfortable with the ideas and values that underpin the formative assessment project. Many of them have 
described their experience as a process of rediscovery, of remembering what attracted them to become teachers, and of the joy of watching learners growing in confidence and competence. The ideas of formative assessment and its potential to enhance the learning environment have seemed to resonate with many teachers' 'memories' of better times; particularly of less pressured classrooms where there was more space for learning. Whether or not this is a case of viewing the past through rose-tinted spectacles, such sentiments are indicative of the tensions that many teachers feel in their working lives. Despite the ideological commitment of many teachers to learner centred classroom strategies, they have found the adoption of such approaches to be problematic. The contexts within which teachers operate would seem to be the major problem. An example is provided by one teacher:

Since August last year, I have been using various Project 1 strategies for Mental Maths and Creative Writing. I am delighted with the results. The biggest thing I got out of the project is that I have created confident learners who approach their writing and Mental Maths with enthusiasm. I am delighted at the quality of written work my kids can now produce.

However, (and here comes the BUT...) what relevance do the National Tests have in light of the teaching and learning formats being used in Project 1? The kids were so used to working with a buddy partner and having a longer wait time that when we began the National Tests, the peer support was suddenly taken away and kids were left to attempt a formal test on their own. The first paper in Maths is a TIMED response!!!! The standard of work in the written paper was way down on what the kids usually produced. They couldn't continuously assess each other's 
writing as they had been used to. I felt really sorry for my kids so it's partly on their behalf that I'm standing on my soapbox!

The kids all passed the Maths and writing papers but that's not the point. If Project 1 is to be taken into classrooms and implemented on a whole school basis then I feel that there is no place for the National Tests in their current format (email sent by teacher, Lochview Academy to project officer, 2003),

The fears expressed by this teacher indicate that the major concern for project is the issue of sustainability. Clearly Assessment is for Learning has a number of inherent advantages in promoting and sustaining change. First, it is a national programme funded by the Scottish Executive and therefore obviously has political support; the post election joint statement by the Labour and Liberal Democrat leaders, a Partnership for a Better Scotland (Scottish Labour Party and Scottish Liberal Democrats, 2003) has recently made Executive support for assessment for learning even more explicit. Second, as described previously, many teachers have found the focus on learners and learning attractive professionally. Third, the ideas have emerged from widely respected and publicised research findings, supported by the authentic classroom practice of teachers who reported positive differences in learning and attitude. Fourth, although initially suspicious of the concept of an open-ended project, many of the teachers quickly became enthused about a model of development that provided real opportunities for practitioner autonomy. Finally many teachers appear to appreciate an approach where researchers, policy makers and teachers were open about the real challenges being faced in the project and had no readymade 'Blue Peter' solutions to offer. However problematic, the attempt to engage in the 
construction of a learning community appeared to be a key factor in engaging teachers, researchers and policy makers.

Hargreaves and Fullan argue that:

The seeds for development will not grow if they are cast on stony ground. Critical reflection will not take place if there is neither time nor encouragement for it. Teachers will learn little from each other if they work in persistent isolation. (Hargreaves \& Fullan, 1992, p. 13)

Time and support, resourced by centrally allocated funding, have acted as powerful scaffolding within the project. For the teachers involved, support, especially people centred support, has been an important theme. Headteachers, in particular, appear to have the potential to act as powerful contextual catalysts if teachers are convinced of their real and demonstrable commitment to the innovation. Most commonly teachers valued support from other teachers, from the people they perceived most closely linked to their own circumstances. They valued the opportunity to talk with teachers from other schools. In this paper we have constructed teachers as learners operating within a social milieu; regular dialogue with other professionals is an important form of scaffolding within such a process.

Whilst there is no doubt that this project has resulted in positive change for the majority of the teachers and schools involved in it, there still remain a small number of instances where change has been less immediately obvious. Our interpretive analysis has suggested a number of possible reasons for this, and more research is required to further illuminate the issues. However it is our opinion that the lack of immediate success in some cases is not indicative of flaws in the approach adopted, but rather that fine tuning is necessary to 
what is in effect an emerging methodology for promoting sustainable change in educational settings. Moreover, the variability of success within the pilot project indicates the risks posed to future sustainability, particularly due to the existence of the powerful and deeply ingrained contextual inhibitors alluded to by the teacher from Lochview Academy. The tender shoots of formative assessment will find it difficult to thrive in a climate dominated by evidence-driven assessment for measurement. The formative assessment project is an alternative to the driving up standards dream (Black, 2001), a means of enhancing achievement through collaboration. The project on formative assessment has demonstrated that such collaboration, although complex and problematic, is possible. But if, after considering the findings from this first group of project schools, researchers, policy makers and practitioners return to their individual worlds (Hammersley, 2002), then we will witness just one more innovation hurricane. If we regress to talk of rolling out the programme to schools across Scotland, using traditional centre-periphery models of dissemination, any change achieved will be short-lived. To ruffle the calm of the ocean floor, and thereby create lasting pedagogic change, we must build from the important features of success in the project schools and gradually 'grow' the programme in increasing numbers of schools, involving increasing numbers of teachers. This process for real participative change suggests a far longer timeframe for change than recent policy innovations have allowed; a timeframe that will require political will to initiate and political courage to sustain. Most of all we should bear in mind Eisner's (1996) caveat: that reform is ultimately futile if teachers do not understand and own the reform in question. 


\section{ACKNOWLEDGEMENT}

This paper has been a collaborative effort from the outset, and many colleagues have contributed helpful insights. In particular, the authors wish to thank Julie Allan, Peter Cope, Richard Edwards, Nicki Hedge and Michael Peters for comments on drafts of the paper.

\section{REFERENCES}

BALL, S. J. (2001) 'You’ve been NERFed!’ Dumbing down the academy: National Educational Research Forum: ‘a national consultation- consultation paper’: a brief and bilious response, Journal of Educational Policy, 16, pp. 265-268

BLACK, P. AND WILIAM, D. (1998a) Assessment and Classroom Learning, Assessment in Education, 5, pp. 7-68

BLACK, P. AND WILIAM, D. (1998b) Inside the black box: raising standards through classroom assessment (London, King’s College)

BLACK, P. (2001) Dreams Strategies and Systems: portraits of assessment past, present and future, Assessment in Education, 8, pp. 65-85

BLACK, P., HARRISON, C., LEE, C., MARSHALL, B. AND WILIAM, D. (2002) Working inside the black box: assessment for learning in the classroom (London, King's College)

BRYCE, T. AND HUMES, W. (1999) Scottish Secondary Education: Philosophy and Practice, in: T. BRYCE AND W. HUMES (Eds) Scottish Education (Edinburgh, Edinburgh University Press) 
COWLEY, T. AND WILLIAMSON, J. (1998) A recipe for success? Localised implementation of a (flexible) National Curriculum, The Curriculum Journal, 9, pp. $79-94$

CUBAN, L. (1994) How teachers taught: constancy and change in American classrooms 1890-1980 (New York, Teachers College Press)

DOYLE, W. AND PONDER, G.A. (1977) The Practicality Ethic in Teacher DecisionMaking, Interchange, 8, pp. 1-12

EISNER, E. (1996) Curriculum and Cognition Reconsidered (London, Paul Chapman Publishing)

FULLAN, M. (1993) Change Forces: probing the depths of educational reform (London, The Falmer Press)

GADAMER, H-G. (1977) Philosophical Hermeneutics (Berkeley, University of California Press)

GOODSON, I.F. (1994) Studying Curriculum (Buckingham, Open University Press)

GUILE, D. (2003) From Credentialism to the Practice of Learning for the Knowledge Economy, Policy Futures in Education, 1, pp. 83-105.

HALLAM, S., KIRTON, A., PFEFFERS, J., ROBERTSON, P. \& STOBART, G. (2003) Interim Report of the Evaluation of Programme One of the Assessment Development programme: support for professional practice in formative assessment - Interim Report (Institute of Education, University of London)

HAMMERSLEY, M. (2002) Educational Research, Policymaking and Practice (London, Paul Chapman Publishing) 
HARGREAVES, A. (1994) Changing Teachers, Changing Times: teachers' work and culture in the post-modern age (London, Cassell)

HARGREAVES, A. (1997) Series Editor’s Forward, in: G. HELSBY AND G. MCCULLOCH (Eds) Teachers and the National Curriculum (London, Cassell)

HAYWARD, L., KANE, J. AND COGAN, N. (2000) Improving Assessment in Scotland: Report of the National Consultation on Assessment in Scotland (Glasgow, University of Glasgow)

HELSBY, G. AND MCCULLOCH, G. (1997) Teachers and the National Curriculum (London, Cassell)

LEVIN, B. (1998) An Epidemic of Education Policy: (what) can we learn from each other?, Comparative Education, 34, pp. 131-141

MADISON, G.B. (1999) Hermeneutics: Gadamer and Ricoeur, in: R.H. POPKIN (Ed) The Pimlico History of Western Philosophy (London, Pimlico)

OLSON, J. (2002) Systemic change/teacher tradition: legends of reform continue, Journal of Curriculum Studies, 34, pp. 129-137

OSBORN, M., CROLL, P., BROADFOOT, P., POLLARD, A., MCNESS, E. AND TRIGGS, P. (1997) Policy into Practice and Practice into Policy: creative mediation in the primary classroom, in: G. HELSBY AND G. MCCULLOCH (Eds) Teachers and the National Curriculum (London, Cassell)

PAECHTER, C. (1995) Crossing Subject Boundaries: the micropolitics of curriculum innovation (London, HMSO) 
POPKEWITZ, T.S. (1997) The Production of Reason and Power: curriculum history and intellectual traditions, Journal of Curriculum Studies, 29, pp. 131-164

PRIESTLEY, M. (2002) Global discourses and national reconstruction: the impact of globalization on curriculum policy, The Curriculum Journal, 13, pp. 87-104

PRIESTLEY, M. (2003) A fusion of past and present: the importance of context, impetus, scaffolding and classroom experience in sustaining curriculum change, working paper, University of Stirling

SCOTTISH LABOUR PARTY AND SCOTTISH LIBERAL DEMOCRATS (2003) A Partnership for a Better Scotland: Partnership Agreement, online http://www.scotland.gov.uk/library5/government/pfbs-00.

SENGE, P. AND SCHARMER, O. (2001) Community Action Research, in: P. REASON AND H. BRADBURY (Eds) Handbook of Action Research (London, Sage Publications)

SOED (1991) Curriculum and Assessment in Scotland: Assessment 5-14 (Edinburgh, HMSO)

SPILLANE, J. (1999) External reform efforts and teachers' initiatives to reconstruct their practice: the mediating role of teachers' zones of enactment, Journal of Curriculum Studies, 31, pp. 143-175

STRONACH, I. AND MORRIS, B. (1994) Polemical Notes on Educational Evaluation in the Age of Policy Hysteria, Evaluation and Research in Education, 8, pp. 5-19 
SWANN, J. AND BROWN, S. (1997) The implementation of a National Curriculum and teachers’ classroom thinking, Research papers in Education: Policy and Practice, 12, pp. 91-114

TORRANCE, H. AND PRYOR, J. (2001) Developing Formative Assessment in the Classroom: using action research to explore and modify theory, British Educational Research Journal, 27, pp. 615-631

VYGOTSKY, L. S. (1978) Mind in Society (Cambridge, Harvard University Press)

WILIAM, D. AND LEE, C. (2001) Teachers' Developing Assessment for Learning: impact on student achievement, British Educational Research Association Conference Paper, University of Leeds 